\title{
Carob tree micropropagation essays (Ceratonia siliqua L.)
}

\author{
Sara $\mathrm{Nia}^{1, *}$, Malika Abid ${ }^{1}$, and Ilham Belkoura ${ }^{2}$ \\ ${ }^{1}$ Department of biology. FS Oujda, Morocco \\ ${ }^{2}$ Department of basic sciences. National School of Agriculture, Meknes, Morocco
}

\begin{abstract}
Carob tree (Ceratonia siliqua L.) is an agro-sylvo-pastoral species that has been classified among the most efficient trees. The first publications on the "in-vitro" multiplication of Carob are very recent and show conflicting results. Mastery of this technique seems necessary to provide the increased demand of the international market for the gum extracted from the endosperm of the seed, a polyoside called galactomannan. This work aimed to study micropropagation from adult tree micro cuttings. Our results showed that the most favorable disinfectant is $\mathrm{HgCl}_{2}$ with $93 \%$ surface sterile explants. Comparison of the effect of various hormones with different concentrations (BAP, Zeatin, GA3, TDZ, and ANA) has shown that the addition of BAP on MS medium gave a good response of axillary bud development $(58,3 \% \pm 6,42)$ while BAP supplemented with activated charcoal gave the best results $(87,3 \% \pm 4,23)$. As for rooting, the different alternatives of hormones types and concentrations must be later considered to initiate rooting of the buds.
\end{abstract}

\section{Introduction}

Mediterranean ecosystems suffer from scarce or irregular rainfall and long dry summer periods combined with high anthropogenic pressure, leading to irreversible degradation of the vegetation cover and rapid soil erosion. Faced with this critical situation, reforestation becomes an absolute necessity to conserve soil fertility and improve the standard of living of the rural population by using pioneer multipurpose tree species adapted to climatic hazards and marginal and eroded land the carob tree $[1,2]$. In addition to its rusticity, its indifference towards the nature of the soil, its quality wood, its ornamental and landscape value, this species acquires an interest increasingly growing at the level of Morocco, because of its seeds whose industrialization knows a remarkable development and of the commercial transactions with a value which exceeds by far that of the ligneous production. Thus, the pulp, seeds, and gum are subject to an essential trade towards Europe. Moreover, previous studies showed that the Moroccan cultivars are characterized by a high yield of seeds that provide a high yield of the endosperm.

As a result, the kingdom is constantly improving its products to ensure a good supply to the local industry to extract gum $[1,3]$. Given the importance given to the carob tree in recent years, traditional propagation techniques could not satisfy the increased need for this plant. Therefore, the use of in vitro culture represents a significant challenge and a promising solution [4]. Therefore, the purpose of this study was to shine new light on these debates and to optimize reliable methods for rapid propagation of this species with a focus on micropropagation by micro-cutting

\footnotetext{
*Corresponding author: niasarah041@gmail.com
}

\section{Material and Methods}

\subsection{Sterilization and establishment of plant material}

Shoots of the current year or young offshoots were collected during different periods: September, February, and May, from the same adult female tree (under rainfed conditions in Meknes), to surmount the genotypic effect.

Explants were defoliated just after collection and surface disinfected with running water and Tween 80 to remove surface impurities, shoots were placed for $2 \mathrm{~min}$ in ethanol $70 \%$, and later two disinfectants were tried (inside the laminar airflow cabinet) in order to control contaminations: $\mathrm{HgCl} 2(0,5 \mathrm{~g} / \mathrm{l}, 1 \mathrm{~g} / \mathrm{l}, 2 \mathrm{~g} / \mathrm{l}$ for 3 or $5 \mathrm{~min})$ and commercial bleach solution - NaCIO $\left(12^{\circ}\right)$-for different times $(10,15,20$ and 30min), and were washed with SDW 3 times.

\subsection{Axillary bud induction}

Only one primary nutrient medium was used for disinfection tests and consisted of MS medium supplemented with sucrose $(20 \mathrm{~g} / \mathrm{l})$ as a carbon source. Then, the medium was solidified with agar $(8 \mathrm{~g} / 1)$.

The compilation of data was done after four weeks, during which time the percentage of sterile surface explants is estimated. 


\subsection{Shoot multiplication}

In order to stimulate the response of axillary bud development, the treatments consisted of culturing shoot explants for eight weeks on MS medium supplemented with different phytohormones.

- M1: MS +30g/l sucrose +8g/l agar + BA(0,5mg/l)

- M2: MS +30g/1 sucrose $+8 \mathrm{~g} / 1$ agar $+\mathrm{BA}(0,5 \mathrm{mg} / \mathrm{l})+\mathrm{AC}$ $(1 \mathrm{mg} / \mathrm{l})$

- M3: MS +30g/l sucrose $+8 \mathrm{~g} / \mathrm{l}$ agar $+\mathrm{ANA}(0,5 \mathrm{mg} / \mathrm{l})+$ GA3(0,5mg/l)

The compilation of data was done after eight weeks.

\subsection{Rooting induction}

The rooting process was separated into two treatments: Shoots were cultured on darkness on:

- M1: MS/2+ sucrose (20g/1) + IBA $(0,5 \mathrm{mg} / \mathrm{l})$

- M2: MS/2+ sucrose $(20 \mathrm{~g} / \mathrm{l})+\operatorname{IBA}(0,5 \mathrm{mg} / \mathrm{l})+$ agar $(7 \mathrm{~g} / \mathrm{l})$

- M3: MS/2 sucrose (20g/l) + ANA (0,5mg/l)

- M4: MS/2+ sucrose (20g/) 1+ ANA $(0,5 \mathrm{mg} / \mathrm{l})+$ agar $(7 \mathrm{~g} / \mathrm{l})$

After 4 weeks, Shoots were transferred to the basal medium: $\mathrm{MS} / 2+$ sucrose $(20 \mathrm{~g} / \mathrm{l})+\operatorname{agar}(7 \mathrm{~g} / \mathrm{l})$ and incubated under the same light and temperature regime as shoot multiplication cultures.

\section{Results and discussion}

\subsection{Establishment of Carob axenic cultures}

\subsubsection{Effect of the disinfectant}

In order to control contaminants, two sterilizing agents were tried at various concentrations and different times. Pearson's chi-squared test indicated a statistically significant difference between the two sterilizing agents. $\mathrm{HgCl}_{2}$ is more effective with $93,3 \%$ of sterile surface explants than $\mathrm{NaClO}$ with only $50 \%$ of disinfection, as shown in Table1. This result follows previous studies that showed that $\mathrm{HgCl}_{2}$ treatment for $5 \mathrm{~min}$ is an effective decontamination procedure in tissue culture [5].

Table 1. Effect of the disinfectant agents on contamination rate (Pearson's chi-squared test).

\begin{tabular}{|c|c|c|}
\hline & NaClO & $\mathbf{H g C l}_{\mathbf{2}}$ \\
\hline $\begin{array}{c}\text { Contamination } \\
\text { rates }\end{array}$ & $50 \% \pm 9,28$ & $6,7 \% \pm 4,63$ \\
\hline $\begin{array}{c}\text { p-value (Pearson's } \\
\text { chi-squared test) }\end{array}$ & \multicolumn{2}{|c|}{0,000} \\
\hline
\end{tabular}

\subsubsection{Effect of the season}

It has been found that carob regeneration processes in producing in vitro plants are more desirable from explants originated from suckers collected in summer. Indeed, the highest percentage of regenerated explants
(90\%) and the highest number of explants with free contamination $(76,7 \%)$ were obtained.

\subsubsection{Effect of the explant's position on the branch}

Statistical analysis indicates that the position of the explants on the branch has a significant effect on the cultural establishment. Results show that apical explants give a better budburst rate $(27,8 \%)$. Moreover, young suckers give the best survival rates and surface-free contamination since, with young suckers, more than $98 \%$ of disinfection was achieved.

\subsection{Axillary Buds development}

\subsubsection{Effect of plant growth regulators on shoot development of Ceratonia siliqua}

Shoot development has reached during the second week of culture before transfer to hormone-rich media. Statistical analysis has shown a significant effect of the media on shoot development rates. Our results indicate that MS supplemented with BAP furthered the development of several buds in the same node. This may be the result of the expression of existing adventitious buds in the same node. Moreover, stems and leaves growing were improved by adding activated charcoal $(87,3 \% \pm 4,23)$ as this component counteracts browning and prevents tissue necrosis(Table 2 ).

Similar results have been reported on the efficacy of BAP alone on shoot development [6-9].

Table 2. Effect of plant growth regulators on budburst development

\begin{tabular}{|c|c|c|c|}
\hline & MS+BAP & MS+BAP+AC & $\begin{array}{c}\text { MS+ANA+G } \\
\mathbf{A 3}\end{array}$ \\
\hline $\begin{array}{c}\text { Budburst } \\
\text { development }\end{array}$ & $58,3 \% \pm 6,42$ & $87,3 \% \pm 4,23$ & $35,1 \pm 6,38$ \\
\hline $\begin{array}{c}\text { p-value } \\
\text { (Pearson's chi- } \\
\text { squared test) }\end{array}$ & \multicolumn{3}{|c|}{0,000} \\
\hline
\end{tabular}

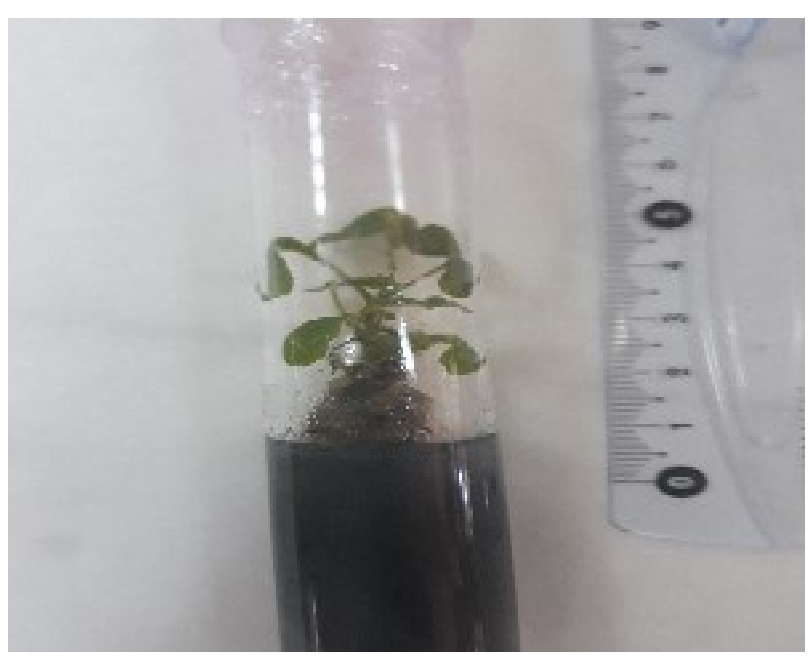

Fig. 1. Shoot-culture at the end of multiplication phase in MS medium 


\subsubsection{Effect of plant growth regulators on the development of new shoots}

Analysis and simulation indicate that the media does not significantly affect the elongation of new shoots. However, the number of leaves per new shoot (Table 3) is high $(4,76 \% \pm 0,29)$ in the presence of BAP compared to ANA and GA3 $(1,33 \% \pm 0,26)$.

Table 3. Effect of plant growth regulators on the development of new shoots

\begin{tabular}{|c|c|c|c|}
\hline & $\begin{array}{c}\text { Mean } \\
\text { number of } \\
\text { new shoots }\end{array}$ & Length & $\begin{array}{c}\text { Mean number } \\
\text { of leaves per } \\
\text { shoot }\end{array}$ \\
\hline ANA+GA3 & $1,067 \% \pm 0,06$ & $\begin{array}{c}0,293 \% \pm \\
0,71\end{array}$ & $1,33 \% \pm 0,26$ \\
\hline BAP & $2,233 \% \pm 0,60$ & $\begin{array}{c}0,793 \% \pm \\
0,24\end{array}$ & $4,76 \% \pm 0,29$ \\
\hline $\begin{array}{c}\text { Significance of } \\
\text { one-way ANOVA } \\
(\alpha=0.05)\end{array}$ & 0,061 & 0,057 & 0,012 \\
\hline
\end{tabular}

\subsection{Rooting}

One month after the induction, no rooting was detected. However, the appearance of callus at the base of the explants was considerable, especially in the liquid IBA medium. Although 15 days after transfer to a medium devoid of auxins in the light, we did not note any case of rooting.

The chi-square test demonstrated that the medium has a significant effect on callus production. Moreover, our results indicated that the juvenility of the used shoots has a significant effect on both phenomenons. The absence of rooting in the case of shoots resulting from micro-cutting is undoubtedly due to the age of the shoot, which remains the same age as the initial explant. Therefore, it would be interesting to do a looped microcutting first for the intensification of the plant material and then for the rejuvenation of the shoots because the younger the material is, the greater the rooting.

\section{Conclusion}

This is the first report on in vitro propagation from suckers of the carob tree, which presented a more accessible adaptation to in vitro culture and higher rates of in vitro initialization than explants from shoots of the branch. In vitro rooting of Carob shoots are unsuccessful, and different alternative hormones types and concentrations must be later considered to initiate rooting of the buds.

\section{References}

1. Ait Chitt M., Belmir $\mathrm{H}$ et Lazrak A., 2007. Production de plants sélectionnés et greffés de caroubier. Transfert de technologie en agriculture. Maroc. $\mathrm{N}^{\circ} 153,1-4 \mathrm{pp}$.
2. Benmahioul B., Kaid-Harche M et Daguin F., 2011. Le caroubier, une espèce Méditerranéenne à usages multiples. In Forêt méditerranéenne, $\mathrm{N}^{\circ} 1,51-58 \mathrm{pp}$.

3. Battle I. \& Tous J., (1997). Carob tree. Ceratonia siliqua L. Promoting the conservation and use of underutilized and neglected crops. 17. Institute of Plant Genetic and Crops Plant Research. Gatersleben/International Plant Resources Institute. Rome. Italy. 92 p.

4. Naoual Gharnit \& Abdeslam Ennabili (2015): Categories of Carob Tree (Ceratonia siliqua L.) from Morocco, International Journal of Fruit Science, DOI: $10.1080 / 15538362.2015 .1102674$

5. A. Romano, S. Barros, M.A, MartinsLoucao,M.A.(2002). Plant Cell Tiss. Organ Cult. 68, 35-41.(2002).

6. T. Hsina ,N. Elmtili . Cahiers UAE, 7-12. .(2012).

7. R. Saïdi , B. El bouzdoudi, M B.Kbiach, A. Lamarti , A. J. Mater. Environ. Sci, 6(8), 2330-2337. (2015).

8. Shahzad, R. Akhtar, NA. Bukhari . K. Trees:1-15. (2017).

9. El Bouzdoudi , R. Saïdi, Z.N. El Ansari, M.L. El Kbiach, P. Martin, A. Badoc, A.Lamarti. American Journal of Plant Sciences, 8, 2180-2195. (2017). 